\title{
Food intake survey of kindergarten children in Korea: Part 3 cadmium and lead burden
}

\author{
Takao Watanabe ${ }^{1}$ Eul-Sang Kim ${ }^{2}$ - Yang-Sook Ko ${ }^{3} \cdot$ Hye-Ran Yang ${ }^{4} \cdot$

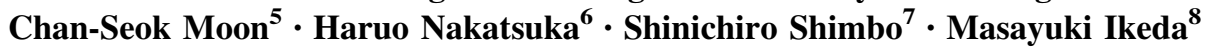

Received: 17 March 2015 / Accepted: 13 April 2015/Published online: 21 May 2015

(C) The Japanese Society for Hygiene 2015

\begin{abstract}
Objectives This study was initiated to elucidate the extent of dietary exposure of children in Korea to two pollutant metals of cadmium $(\mathrm{Cd})$ and lead $(\mathrm{Pb})$. Possible urbanrural difference was also examined.

Methods Food duplicate and morning spot urine samples were collected from 108 children in 4 kindergartens (KG) (1 KG in Seoul and $3 \mathrm{KGs}$ in Jeju Island), as reported in a previous publication. The samples were analyzed for $\mathrm{Cd}$ and $\mathrm{Pb}$ by ICP-MS.

Results $\mathrm{Cd}$ and $\mathrm{Pb}$ in food duplicate and urine samples were distributed approximately log-normally. Geometric means for $\mathrm{Cd}$ and $\mathrm{Pb}$ in food duplicate samples were 12.4
\end{abstract}

E.-S. Kim: Deceased.

Masayuki Ikeda

m-71-ikeda@nifty.com

1 Department of Childhood Education, Faculty of Human Sciences, Tohoku Bunkyo University, Yamagata 990-2316, Japan

2 Department of Food and Nutrition, Dankook University, Yongin, Gyeonggi 448-701, Korea

3 Department of Food and Nutrition, Jeju National University, Jeju 690-756, Korea

4 Seoul Metropolitan Government Research Institute of Public Health and Environment (the Food and Drug Division), Seoul 137-734, Korea

5 Department of Industrial Health, Catholic University of Pusan, Busan 609-757, Korea

6 School of Nursing, Miyagi University, Taiwa-cho 981-3298, Japan

7 Kyoto Women's University, Kyoto 605-8501, Japan

8 Kyoto Industrial Health Association, Kyoto 604-8472, Japan and $5.8 \mu \mathrm{g} / \mathrm{day}$, or 0.58 and $0.27 \mu \mathrm{g} / \mathrm{kg}$ body weight/day, respectively, and the values for $\mathrm{Cd}$ and $\mathrm{Pb}$ in urine (as observed, i.e., with no correction for urine density) were 0.91 and $1.64 \mu \mathrm{g} / \mathrm{L}$, respectively. 2.41 and $0.30 \mu \mathrm{g} /$ day of $\mathrm{Cd}$ and $\mathrm{Pb}$ (accounting for 19.5 and $5.1 \%$ ) came from boiled rice, the staple food. The levels of $\mathrm{Cd}$ and $\mathrm{Pb}$ burden among the children in the present survey were essentially the same with the levels reported for children in Pusan. The reasons for difference in the rank in Cd-D and Cd-U among the 4 KGs need further study.

Conclusions The observed levels of $\mathrm{Cd}$ and $\mathrm{Pb}$ exposure were more or less similar to what were reported for children in Pusan. No apparent urban-rural difference could be detected.

Keywords Cadmium - Children · Daily foods · Korea . Lead

\section{Introduction}

Cadmium $(\mathrm{Cd})$ and lead $(\mathrm{Pb})$ are among the most often studied environmental pollutant metals [1-5]. After a longterm exposure to $\mathrm{Cd}$ via food (including water), $\mathrm{Cd}$ may adversely affect renal tubules and then calcium metabolism in bones, typically in aged subjects [6]. In contrast, elevated $\mathrm{Pb}$ levels in blood may induce retarded development of the central nervous system function in the early stage of life [6, 7]. It is known that the major source of $\mathrm{Cd}$ for general population is foods, whereas that for $\mathrm{Pb}$ is environmental air in addition to foods due to use of organic lead as an anti-knocking agent in automobile fuels [8,9]. It would be worthy to note that $\mathrm{Cd}$ levels in polished rice, the staple food for general populations in many areas in East and South-East Asia, was the second [10] or sixth highest 
[11] in Korea among the areas surveyed. Despite the knowledge of ubiquitous presence of these metals, reports on human epidemiology regarding dietary intake of $\mathrm{Cd}$ and $\mathrm{Pb}$ via foods are still scarce in Korea [12-16]. In fact, only one report is available for intake by children [17].

It is the purpose of this communication to report on dietary intake of children in kindergarten (to be abbreviated as $\mathrm{KG}$ ) and to alleviate the information shortage. It should be added that the surveys were conducted in Seoul as a representative metropolis, and in Jeju Island as a typical rural area.

\section{Materials and methods}

\section{Survey sites and survey subjects}

The details of study locations and study populations were described in Part 1 of this series of articles [18]. In short, 108 boys and girls participated in this study. They attended 4 kindergartens $(\mathrm{KG})$ in Korea, i.e., 33 children KG 1 in Seoul, 37 children in KG 2 in Jeju city, 18 children in KG 3 in a village in Jeju Island and 20 children in KG 4 in another village in the island. Their mothers provided informed consent and food duplicate samples (including any drinks) the children took in the past $24 \mathrm{~h}[19,20]$. Morning spot urine samples were also collected from the children. The study protocol was approved by the Institutional Review Board of Dankook University (DKU2015-03-005), Yongin-si, Gyeonggi-do 448-701, Korea.

\section{Instrumental analysis}

The food duplicate, urine and a small portion (ca. $5 \mathrm{~g}$ ) of boiled rice samples were wet-ashed by heating in the presence of mineral acids as previously described in Part 2 of this series of articles [21]. The wet-ashed liquid samples were subjected to ICP-MS (inductively coupled plasmamass spectrometry) analyses for $\mathrm{Cd}$ and $\mathrm{Pb}$ determination. The samples from KG 1 in Seoul were analyzed in an analytical laboratory in Shimadzu Techno-research, Inc., Kyoto, Japan, whereas the samples from KGs 2, 3 and 4 in Jeju Island were analyzed in Kyoto Women's University [22]. The performances of both laboratories were excellent; the quality of the analysis in the former laboratory was approved by International Organization for Standardization (ISO) 17025 , and the performance in the latter laboratory was detailed in Shimbo et al. [22]. Thus, the analysis results from the two laboratories were considered to be compatible to each other. The quantification limits [23] in the former and the latter laboratories were 0.1 and $0.04 \mathrm{ng} /$ $\mathrm{g}$ for $\mathrm{Cd}$, and the limits were 1.0 and $0.8 \mathrm{ng} / \mathrm{g}$ for $\mathrm{Pb}$, respectively.

\section{Statistical analysis}

Both $\mathrm{Cd}$ and $\mathrm{Pb}$ concentrations in the food duplicate, boiled rice and urine samples were distributed log-normally, and, therefore, geometric means (GMs) and geometric standard deviations (GSDs) were taken as parameters to represent distributions. One-way analysis of variance followed by post hoc test (Scheffe) (taking KGs as independent variables and one of the values for $\mathrm{Cd}$ and $\mathrm{Pb}$ as dependent variable) was employed to detect possible inter-KG difference in $\mathrm{Cd}$ and $\mathrm{Pb}$ levels after logarithmic conversion of the values. Correlation analyses were also employed. As body size of the children varied among the KGs (for details, see [18]), analysis was made as measured (i.e., in $\mu \mathrm{g} / \mathrm{day}$ ) and also as the rate per $\mathrm{kg}$ body weight of each child (i.e., in $\mu \mathrm{g} / \mathrm{day} / \mathrm{kg}$ body weight/day). Correlation coefficients were also calculated. A probability of $5 \%$ (i.e., $p<0.05$ ) was taken as the point of judgment for significant difference.

\section{Results}

\section{Daily dietary intake of $\mathrm{Cd}$ and $\mathrm{Pb}$}

The results of the measurements for dietary $\mathrm{Cd}$ and $\mathrm{Pb}$ intake ( $\mathrm{Cd}-\mathrm{D}$ and $\mathrm{Pb}-\mathrm{D})$ are summarized in Table 1 in terms of the 4 KGs. The results of statistical analysis are also presented to detect possible differences (see Figs. 1 and 2 for distribution of $\log \mathrm{Cd}-\mathrm{D}$ and $\log \mathrm{Pb}-\mathrm{D}$, respectively). Because body size of children varied among the KGs (as stated above), both daily intake (in $\mu \mathrm{g} /$ day) and the rate of intake/body weight/day were presented. GM for $\mathrm{Cd}$ in a total 108 cases was $12.39 \mu \mathrm{g} /$ day for $\mathrm{Cd}$ and $5.82 \mu \mathrm{g} /$ day for $\mathrm{Pb}$. After adjustment for bodyweight, the values were $0.58 \mu \mathrm{g} / \mathrm{kg} / \mathrm{day}$ for $\mathrm{Cd}$ and $0.27 \mu \mathrm{g} / \mathrm{kg} / \mathrm{day}$ for $\mathrm{Pb}$.

Inter-KG comparison revealed that $\mathrm{Cd}$ intake was the lowest in KG 1 irrespective of on the daily basis or on the $\mathrm{kg}$ /day basis, whereas no inter-KG difference was observed in $\mathrm{Pb}$ intake. When $\mathrm{Cd}$ and $\mathrm{Pb}$ were calculated for the intake via boiled rice, the staple food item, the intakes via boiled rice were 2.41 and $0.30 \mu \mathrm{g} /$ day for $\mathrm{Cd}$ and $\mathrm{Pb}$, respectively. Comparison of the values for boiled rice over total foods revealed that the contributions of boiled rice for $\mathrm{Cd}$ and $\mathrm{Pb}$ accounted for 19.5 and $5.1 \%$, respectively. The rate for $\mathrm{Cd}$ from rice was highest in KG 1 and lowest KG 2 . The reverse was the case for $\mathrm{Pb}$; it was the lowest in $\mathrm{KG} 1$ 

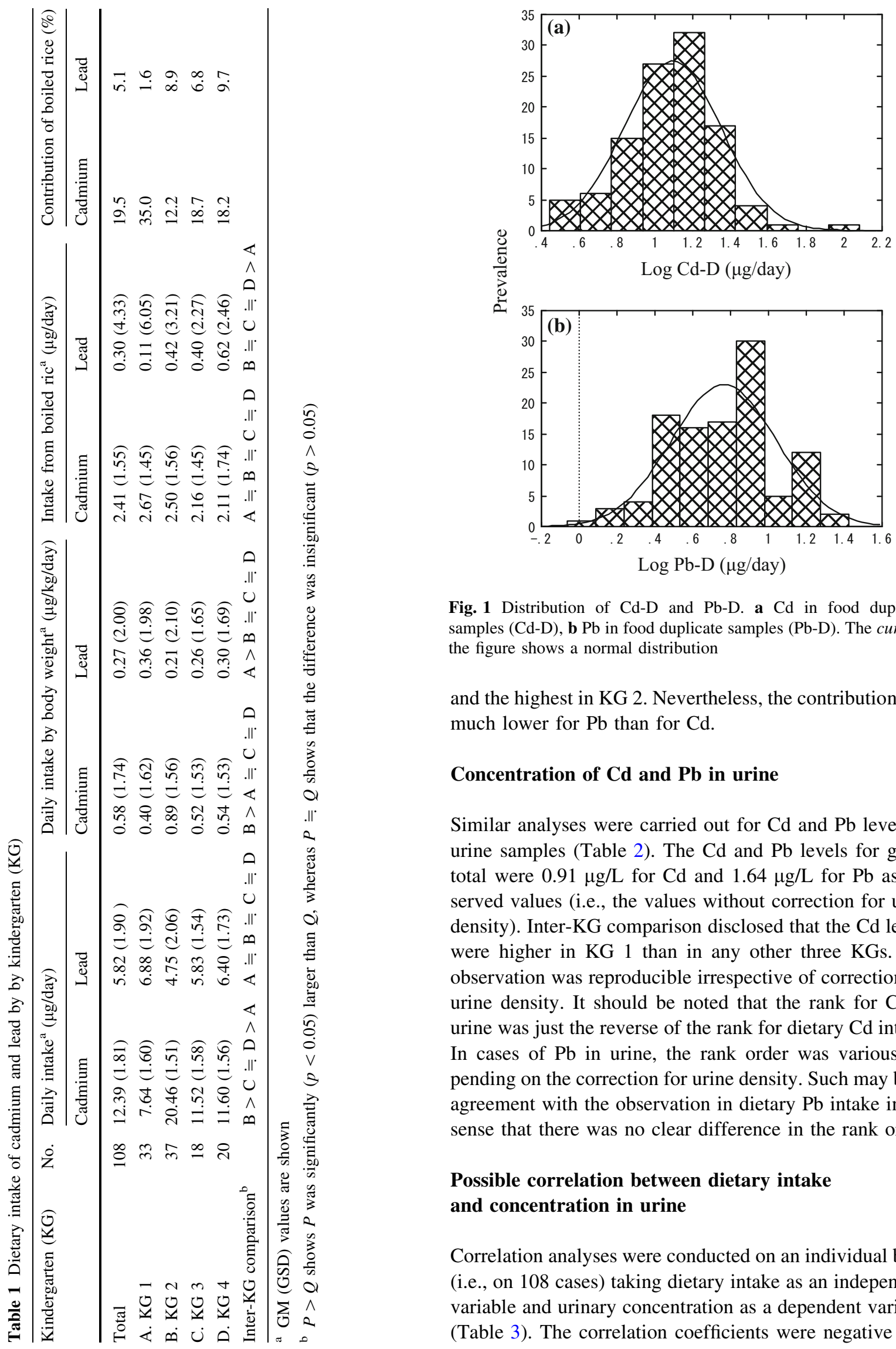

Fig. 1 Distribution of $\mathrm{Cd}-\mathrm{D}$ and $\mathrm{Pb}-\mathrm{D}$. a $\mathrm{Cd}$ in food duplicate samples $(\mathrm{Cd}-\mathrm{D}), \mathbf{b} \mathrm{Pb}$ in food duplicate samples $(\mathrm{Pb}-\mathrm{D})$. The curve in the figure shows a normal distribution

and the highest in KG 2. Nevertheless, the contribution was much lower for $\mathrm{Pb}$ than for $\mathrm{Cd}$.

\section{Concentration of $\mathrm{Cd}$ and $\mathrm{Pb}$ in urine}

Similar analyses were carried out for $\mathrm{Cd}$ and $\mathrm{Pb}$ levels in urine samples (Table 2). The $\mathrm{Cd}$ and $\mathrm{Pb}$ levels for grand total were $0.91 \mu \mathrm{g} / \mathrm{L}$ for $\mathrm{Cd}$ and $1.64 \mu \mathrm{g} / \mathrm{L}$ for $\mathrm{Pb}$ as observed values (i.e., the values without correction for urine density). Inter-KG comparison disclosed that the $\mathrm{Cd}$ levels were higher in KG 1 than in any other three KGs. The observation was reproducible irrespective of correction for urine density. It should be noted that the rank for $\mathrm{Cd}$ in urine was just the reverse of the rank for dietary $\mathrm{Cd}$ intake. In cases of $\mathrm{Pb}$ in urine, the rank order was various depending on the correction for urine density. Such may be in agreement with the observation in dietary $\mathrm{Pb}$ intake in the sense that there was no clear difference in the rank order.

\section{Possible correlation between dietary intake and concentration in urine}

Correlation analyses were conducted on an individual basis (i.e., on 108 cases) taking dietary intake as an independent variable and urinary concentration as a dependent variable (Table 3). The correlation coefficients were negative (i.e., 


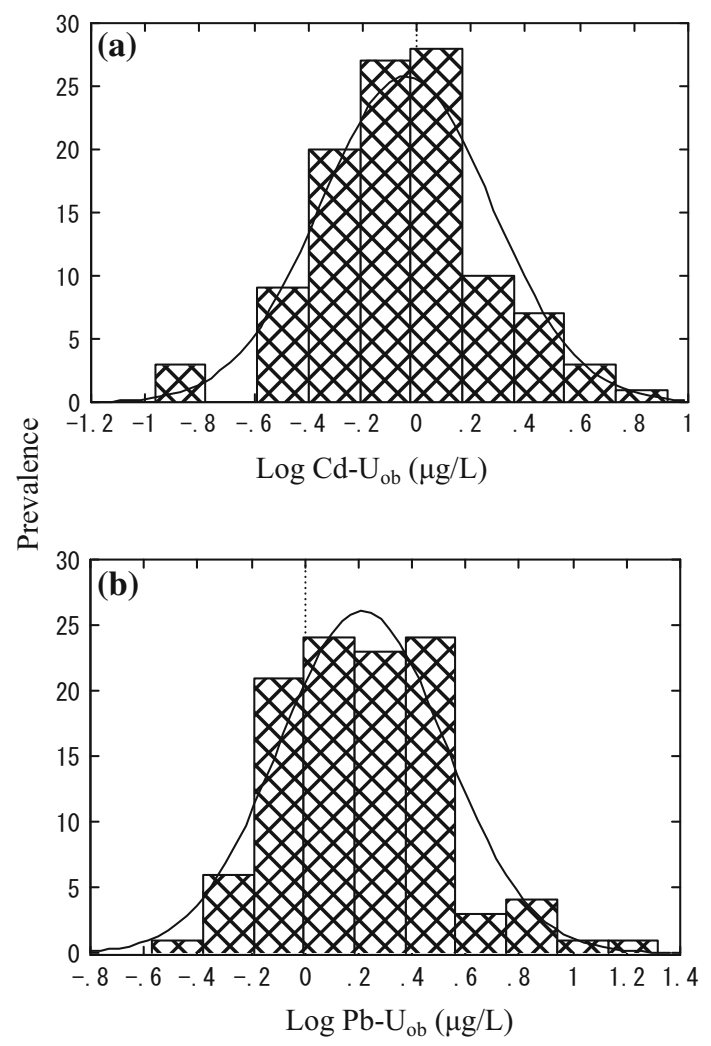

Fig. 2 Distribution of $\mathrm{Cd}-\mathrm{U}_{\mathrm{ob}}$ and $\mathrm{Pb}-\mathrm{U}_{\mathrm{ob}}$. a $\mathrm{Cd}$ in urine (as observed, i.e., with no correction for urine density) $\left(\mathrm{Cd}-\mathrm{U}_{\mathrm{ob}}\right), \mathbf{b} \mathrm{Pb}$ in urine (as observed, i.e., with no corection for urine density) ( $\mathrm{Pb}$ $\mathrm{U}_{\mathrm{ob}}$ ). The curve in the figure shows a normal distribution

$<0$ ) in cases of $\mathrm{Cd}$ and mostly insignificant in cases of $\mathrm{Pb}$. Thus, the observation did not support the expectation that urinary $\mathrm{Cd}$ and $\mathrm{Pb}$ would correlate with dietary intakes.

\section{Food groups as influential sources of dietary $\mathbf{C d}$ and $\mathrm{Pb}$ intake}

As to be discussed later, potatoes $[15,16]$, meats, fish (including shellfish) and seaweeds [17] in addition to cereals $[8,9]$ were suspected as potential sources of $\mathrm{Cd}$ and $\mathrm{Pb}$. Possible association of these food groups with $\mathrm{Cd}$ and $\mathrm{Pb}$ intake was examined by simple regression analysis (Table 4). The results gave significant correlation with $\mathrm{Cd}$ intake for cereals and fish, but not for potatoes, meats and seaweeds. No significant correlation was detected for any food groups as influential $\mathrm{Pb}$ source.

\section{Discussion}

The present study on 108 children in 4 KGs in urban and rural areas made it clear that the overall dietary $\mathrm{Cd}$ and $\mathrm{Pb}$ intake was 12.39 and $5.82 \mu \mathrm{g} /$ day, respectively, or 0.58 and

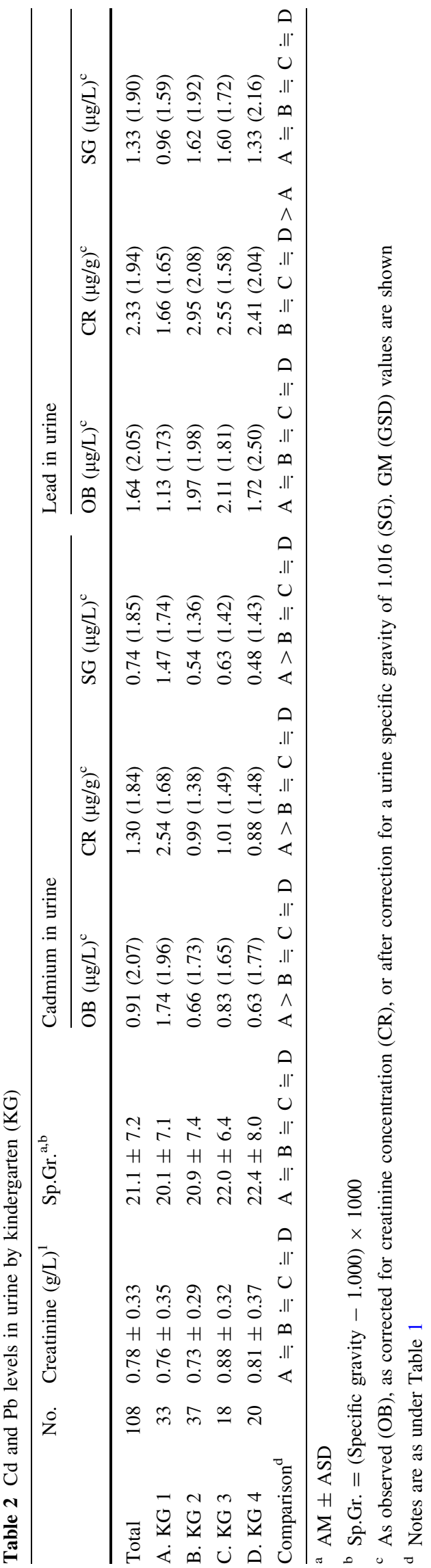


Table 3 Absence of positive correlation of dietary intake of cadmium and lead with urinary concentration

\begin{tabular}{llll}
\hline Dietary intake & Urinary concentration & Corr. Coeff. & $p$ value \\
\hline Cadmium & & & \\
Per day & As observed & -0.489 & $<0.01$ \\
& CR-corrected & -0.430 & $<0.01$ \\
& Sp.Gr.-corrected & -0.384 & $<0.01$ \\
Per body weight per day & As observed & -0.414 & $<0.01$ \\
& CR-corrected & -0.339 & $<0.01$ \\
& Sp.Gr.-corrected & -0.335 & $<0.05$ \\
Lead & & & $\mathrm{ns}$ \\
Per day & As observed & -0.122 & $\mathrm{~ns}$ \\
& CR-corrected & 0.141 & $\mathrm{~ns}$ \\
Per body weight per day & Sp.Gr.-corrected & -0.191 & $\mathrm{~ns}$ \\
& As observed & -0.102 & $<0.05$ \\
& CR-corrected & 0.247 & $\mathrm{~ns}$ \\
\hline
\end{tabular}

CR corrected corrected for creatinine concentration, Sp.Gr.-corrected corrected for urine specific gravity (1.016)

\begin{tabular}{|c|c|c|c|c|c|c|c|c|c|c|}
\hline \multicolumn{2}{|c|}{ Food group } & \multicolumn{5}{|c|}{ Food intake $(\mathrm{g} / \text { day })^{\mathrm{a}}$} & \multicolumn{2}{|c|}{ Corr. with Cd-D ${ }^{c}$} & \multicolumn{2}{|c|}{ Corr. with $\mathrm{Pb}-\mathrm{D}^{\mathrm{c}}$} \\
\hline No. & Name & $\mathrm{AM}$ & ASD & Min & Max & MED & $r^{\mathrm{d}}$ & $p$ & $r^{\mathrm{d}}$ & $p$ \\
\hline 1 & Cereals & 332.8 & 87.6 & 161.9 & 647.7 & 326.9 & 0.25 & $<0.01$ & 0.13 & ns \\
\hline 2 & Potatoes & 22.0 & 32.4 & 0 & 210.3 & 12.9 & -0.09 & $\mathrm{~ns}^{\mathrm{e}}$ & 0.09 & ns \\
\hline 9 & Meats & 42.1 & 38.9 & 0 & 192.6 & 31.6 & -0.04 & ns & 0.13 & ns \\
\hline 11 & Fish $^{\mathrm{b}}$ & 32.5 & 25.8 & 0 & 141.0 & 26.9 & 0.35 & $<0.01$ & 0.09 & ns \\
\hline 12 & Seaweeds & 6.7 & 13.5 & 0 & 80.8 & 2.0 & 0.08 & ns & 0.16 & ns \\
\hline
\end{tabular}

${ }^{\mathrm{a}} n=108$

b Fishes and shellfishes

${ }^{c}$ Correlation coefficient between Cd-D (or Pb-D) and the amount consumed of the food group

${ }^{\mathrm{d}}$ Correlation coefficient

e $n s$ non-significant $(p \geqq 0.05$ )

$0.27 \mu \mathrm{g} / \mathrm{kg} /$ day after correction for body weight (Table 1 ). About 20 and $5 \%$ of $\mathrm{Cd}$ and $\mathrm{Pb}$, respectively, came from boiled rice, the staple food. It was previously observed that foods for children in KG 4 were found to be specific in the sense that the foods there were richer in meat and poultry than foods in other KGs [18]. However, heavy metal contents in meat and poulry (other than organ meats) are known to be lower than the levels in cereals such as rice, the staple food [1], and the amount (i.e., the content multiplied by intake volume) may not affect daily intake levels substantially as observed in Table 1 . The levels in urine (with no correction for urine density) were $0.91 \mu \mathrm{g} / \mathrm{L}$ for $\mathrm{Cd}$ and $1.64 \mu \mathrm{g} / \mathrm{L}$ for $\mathrm{Pb}$ (Table 2).

There was significant and close correlation between $\mathrm{Cd}$ $\mathrm{D}$ and $\mathrm{Cd}-\mathrm{U}$, whereas the correlation between $\mathrm{Pb}-\mathrm{D}$ and $\mathrm{Pb}$ $\mathrm{U}$ was essentially insignificant (Table 3 ). Cd when taken into body will accumulate in renal tubules (in addition to liver), and accumulated $\mathrm{Cd}$ and $\mathrm{Cd}-\mathrm{U}$ are in equilibrium
[24]. $\mathrm{Pb}$ when absorbed will be bound to erythrocytes in peripheral blood and accumulate in bone tissue [24]. Thus, the close correlation of $\mathrm{Cd}-\mathrm{U}$ with $\mathrm{Cd}-\mathrm{D}$, and poor correlation in case of $\mathrm{Pb}-\mathrm{D}$ and $\mathrm{Pb}-\mathrm{U}$ appear to be as expected.

The observation on inter-KG difference that the rank for $\mathrm{Cd}$ in dietary intake did not agree with that for $\mathrm{Cd}$ in urinary levels was puzzling. No clear explanation for the discrepancy is currently available. From toxicological viewpoint, however, the information from urinary levels should be evaluated with care because $\mathrm{Cd}-\mathrm{U}$ is an indicator of a long-term exposure to $\mathrm{Cd}$ [8]. Nevertheless, $\mathrm{Cd}$ in urine also shows significant physiological variation in the levels [25]. In fact, Moon et al. [13] found that both $\mathrm{Cd}-\mathrm{U}$ and Cd-B (Cd in blood) did not correlate with Cd-D. The additional observation that $\mathrm{Pb}-\mathrm{U}$ correlated only weakly with $\mathrm{Pb}-\mathrm{B}$ [13] suggests that $\mathrm{Pb}-\mathrm{U}$ is a poor indictor of $\mathrm{Pb}$ burden, which is in agreement with previous observation [26]. Thus, both Cd-U and Cd-D may need equal attention. 
The point of interest is the comparison of the present findings with levels reported in previous publications. In 2000 in Busan (the second largest city in Republic of Korea), GM Cd-D was $11.2 \mu \mathrm{g} /$ day (or $0.46 \mu \mathrm{g} / \mathrm{kg} /$ day) for 7.5-year-old children and $16.7 \mu \mathrm{g} /$ day (or $0.30 \mu \mathrm{g} / \mathrm{kg} / \mathrm{day}$ ) for their mothers [16]. In a survey conducted in 1994 [12], Cd-D intake by adult women in Busan was $21.2 \mu \mathrm{g} /$ day, and $\mathrm{Pb}-\mathrm{D}$ intake was $20.5 \mu \mathrm{g} /$ day as GM. When the average body weight of $56.1 \mathrm{~kg}$ for mothers in Busan study [17] was applied, Cd-D and $\mathrm{Pb}-\mathrm{D}$ were 0.28 and $0.37 \mu \mathrm{g} /$ $\mathrm{kg} / \mathrm{day}$. The present observation for children, $0.58 \mu \mathrm{g} \mathrm{Cd}$ and $0.27 \mu \mathrm{g} \mathrm{Pb} / \mathrm{kg} /$ day (Table 1 ), may be at a similar level with what were reported in these publications [12, 17].

The present survey disclosed that about 20 and $5 \%$ of daily $\mathrm{Cd}$ and $\mathrm{Pb}$ intake, respectively, came from boiled rice (Table 1). The major source for dietary $\mathrm{Cd}$ intake has been discussed by various authors. In a 1994 survey, Moon et al. [12] found that $23 \%$ of $\mathrm{Cd}$ and $12 \%$ of $\mathrm{Pb}$ in food were attributable to rice. Similar conclusions that cereals and potatoes (in addition to fish and shellfish) are the leading sources of heavy metals in Korean foods were reached in separate studies [15, 16]. Kim et al. [27] in addition pointed out that $\mathrm{Cd}$ and $\mathrm{Pb}$ contents were high in seaweeds. Unfortunately, no data were presented on daily consumption of seaweeds which assumedly may not be high enough to influence daily intake of $\mathrm{Cd}$ and $\mathrm{Pb}$.

As for Cd-U, Lee et al. [28] observed in a nation-wide survey in Korea conducted in 2008 that GM Cd-U was $0.62 \mu \mathrm{g} / \mathrm{L}$ for non-smoking adult Koreans. It appears likely that the present observation of $0.91 \mu \mathrm{g} / \mathrm{L}$ (Table 2) was higher than the national average. $\mathrm{Cd}-\mathrm{U}$ did not differ significantly $(p<0.05)$ between those who consumed fish in the latest 3 days $(0.64 \mu \mathrm{g} / \mathrm{L})$ and those who did not $(0.66 \mu \mathrm{g} / \mathrm{L})$ [28]. However, no details were given regarding the types of fish if it was finned fish (with low $\mathrm{Cd}$ contents) or small squid (with high $\mathrm{Cd}$ contents and edible as a whole).

With regard to urban-rural comparison, Cd-D and $\mathrm{Pb}-\mathrm{D}$ in Seoul, a metropolis, were 14.4 and $16.7 \mu \mathrm{g} /$ day, whereas the counterpart values for Haman, a rural village, were 23.48 and $21.84 \mu \mathrm{g} /$ day. $\mathrm{Cd}-\mathrm{U}_{\mathrm{ob}}$ (i.e., cadmium in urine as observed) were 1.33 and $2.89 \mu \mathrm{g} / \mathrm{L}$ in Seoul and Haman, respectively, and $\mathrm{Pb}-\mathrm{B}$ (i.e., lead in blood) were 49.8 and $34.8 \mu \mathrm{g} / \mathrm{L}$ in the rank [14]. The dietary intake was the exclusive route for $\mathrm{Cd}$ intake whereas both respiratory and dietary intakes are important for $\mathrm{Pb}$ burden $[8,9]$; atmospheric air was more polluted with $\mathrm{Pb}$ in Seoul than that in Haman, whereas dietary $\mathrm{Cd}$ burden may be higher in Haman than that in Seoul. Mutlu and Lee [29] estimated that the long-term $\mathrm{Pb}$ in air in Seoul was $47 \mathrm{ng} /$ $\mathrm{m}^{3}$. No data on $\mathrm{Pb}$ in rural air were presented unfortunately, and it was not possible to make urban-rural comparison on $\mathrm{Pb}$ in atmospheric air. Based on large-scale pilot study of Korean children (including adolescents) on pollutant burden, $\mathrm{Ha}$ et al. [30] reported that the $\mathrm{Pb}-\mathrm{B}$ levels were significantly $(p<0.01)$ higher in urban children $(12.9 \mu \mathrm{g} / \mathrm{L})$ than in rural children $(11.6 \mu \mathrm{g} / \mathrm{L})$, whereas there was no difference in $\mathrm{Cd}$ in blood $(p>0.1)$ between children in urban $(0.30 \mu \mathrm{g} / \mathrm{L})$ and rural areas $(0.30 \mu \mathrm{g} / \mathrm{L})$.

There may be three limitations in the present study. GM Cd-D was the lowest in KG 1 among the 4 KGs whereas the reverse was the case for $\mathrm{Cd}-\mathrm{U}$. Although such disagreement in the rank order was also observed previously by Moon et al. [12], this point apparently needs further study for elucidation. The other limitation would be that ICP-MS analyses were conducted in two laboratories, i.e., samples from KG 1 in one and samples from KGs 2, 3 and 4 in another. The quality assurance data suggested data compatibility between the two laboratories. Nevertheless, it was apparently desirable that whole analyses were conducted in a single laboratory to avoid any inter-laboratory difference in analysis performance. No effect markers in urine such as $\beta_{2}$-microglobulin [1] was studied in the present survey; the absence may also be a limitation. It is, however, quite unlikely that the $\mathrm{Cd}$ and $\mathrm{Pb}$ exposures at the observed levels of the present study may induce any health effects.

The results of the present study, conducted some 10 years ago on 108 children in 4 kindergartens in urban and rural areas in the Republic of Korea, showed that the dietary intake of $\mathrm{Cd}$ and $\mathrm{Pb}$ was 12.4 and $5.8 \mu \mathrm{g} /$ day $(0.58$ and $0.27 \mu \mathrm{g} / \mathrm{kg}$ body weight/day), respectively. $\mathrm{Cd}$ and $\mathrm{Pb}$ levels in urine (as observed, non-corrected value) were 0.91 and $1.64 \mu \mathrm{g} / \mathrm{L}$. These values were generally close to results of studies conducted in later years. No urban-rural differences could be demonstrated clearly.

Acknowledgments The authors are grateful to Dr. K. Jung (the General Director) and Dr. J.-H. Kim (the Director of the Food and Drug Division) of Seoul Metropolitan Government Research Institute of Public Health and Environment, Seoul, Korea, for their interest and support to this work. Thanks are also due to the participating children and their guardians, and administrators and staff of the kindergartens that participated in the study. This work was supported in part by grants from the Ministry of Education, Culture, Sports, Science and Technology, Japan: Grant-in-Aid for Scientific Research C: 22500755 (Head Investigator; T. Watanabe for fiscal years 2010-2012), and Grant-in-Aid for Scientific Research C; 26350150 (Head Investigator; H. Nakatsuka for fiscal years 2014-2016).

Conflict of interest The authors declare that they have no conflicts of interest.

\section{References}

1. International Programme on Chemical Safety (IPCS). Environmental health criteria I34. Cadmium. Geneva: World Health Organization; 1992. 
2. International Programme on Chemical Safety (IPCS). Environmental health criteria 135. Cadmium-environmental aspects. Geneva: World Health Organization; 1992.

3. International Programme on Cheniical Safety (IPCS). Environmental health criteria 3. Lead. Geneva: World Health Organization; 1977.

4. International Programme on Chemical Safety (IPCS). Environmental health criteria 85 . Lead-environmental aspects. Geneva: World Health Organization; 1989.

5. International Programme on Chemical Safety (IPCS). Environmental health criteria 165. Inorganic lead. Geneva: World Health Organization; 1995.

6. Bellinger D, Leviton A, Waternaux C, Needleman H, Rabinowitz M. Longitudinal analysis of perinatal and postnatal lead exposure and early cognitive development. New Engl J Med. 1987;316:1037-43.

7. Jedrychowski W, Perera FP, Jankowski J, Mrozek-Budzyn D, Mroz E, Flak E, Edwards S, Skarupa A, Lisowska-Miszczk I. Very low prenatal exposure to lead and mental development of children in infancy and early childhood. Neuro-epidemiology. 2009;32:270-8.

8. Ikeda M, Zhang ZW, Shimbo S, Watanabe T, Nakatsuka H, Moon CS, et al. Urban population exposure to lead and cadmium in east and south-east Asia. Sci Total Environ. 2000;249:373-84.

9. Ikeda M, Zhang ZW, Shimbo S, Watanabe T, Nakatsuka H, Moon CS, et al. Exposure of women in general populations to lead via food and air in east and southeast Asia. Am J Ind Med. 2000;38:271-80.

10. Watanabe T, Nakatsuka H, Ikeda M. Cadmium and lead contents in rice available in various areas of Asia. Sci Total Environ. 1989;80:175-84.

11. Watanabe T, Shimbo S, Moon CS, Zhang ZW, Ikeda M. Cadmium contents in rice samples from various areas in the world. Sci Total Environ. 1996;184:191-6.

12. Moon C-S, Zhang Z-W, Shimbo S, Watanabe T, Moon D-H, Lee $\mathrm{C}-\mathrm{U}$, et al. Dietary intake of cadmium and lead among the general population in Korea. Environ Res. 1995;71:46-54.

13. Moon CS, Zhang ZW, Shimbo S, Watanabe T, Moon DH, Lee $\mathrm{CU}$, et al. Evaluation of urinary cadmium and lead as markers of background exposure of middle-aged women in Korea. Int Arch Occup Environ Health. 1998;71:251-6.

14. Moon CS, Zhang ZW, Shimbo S, Watanabe T, Lee CU, Lee BK, et al. Evaluation of urinary cadmium and lead as markers of background exposure of middle-aged women in Korea: dietary intake as an influential factor. Toxicol Lett. 1999;108:173-8.

15. Moon CS, Lee CK, Lee JT, Kim JM, Ikeda M. Time trends in dietary cadmium intake of Korean women. Toxicol Res. 2012;1:145-50.

16. Moon CS, Lee CK, Hong YS, Ikeda M. Higher cadmium and lead burden in coastal areas than in inland areas in Korea areas cadmium and lead in blood and urine of middle-aged women in Korea. Asian-Pacific J Clin Nutr. 2014;23:219-24.
17. Moon CS, Paik JM, Choi CS, Kim DH, Ikeda M. Lead and cadmium levels in daily foods, blood and urine in children and their mothers in Korea. Int Arch Occup Environ Health. 2003;76:282-8.

18. Nakatsuka H, Ko Y, Yang HR, Monn CS, Watanabe T, Kin ES, et al. Food intake survey of kindergarten children in Korea: part 1 food, energy, and nutrient intake. Environ Health Prev Med (in press).

19. Acheson KJ, Campbell IT, Edholm OG, Miller DS, Stock MJ. The measurement of food and energy intake in man-an evaluation of some techniques. Am J Clin Nutr. 1980;33:1147-54.

20. Nakatsuka H, Shimbo S, Watanabe T, Yaginuma-Sakurai K. IkedaM. Applicability of food composition tables as a tool to estimate mineral intake of preschool children in Japan: A validation study. J Trace Elem Med Biol. 2013;27:339-45.

21. Yang HR, Ko Y, Watanabe T, Nakatsuka H, Moon CS, Kim ES, et al. Food intake survey of kindergarten children in Korea: part 2 increased dietary intake of tin possibly associated with canned foods. Environ Health Prev Med (in press).

22. Shimbo S, Zhang Z-W, Watanabe T, Nakatsuka H, MatsudaInoguchi N, Higashikawa K, et al. Cadmium and lead contents in rice and other cereal products in Japan in 1998-2000. Sci Total Environ. 2001;281:165-75.

23. Japan Society for Analytical Chemistry (ed.). Analysis and Reliability of the Analysis Results. Tokyo (Japan): Maruzen; 1998. p. 52 (in Japanese).

24. Lauwerys RR, Hoet P. Industrial chemical exposure (3rd ed.) Chap. 2 cadmium, and inorganic lead. Boca Raton et al.: Lewis Publishers; 2001. pp. 54, 104.

25. Yamagami T, Suna T, Fukui Y, OhashiF Takada S, Sakurai H, et al. Biological variations in $\alpha_{1}$-microglobulin, $\beta_{2}$-microglobulin and $N$-acetyl- $\beta$-D-glucosaminidase in adult women in a nonpolluted area. Int Arch Occup Environ Health. 2008;81:263-71.

26. Higashikawa K, Zhang ZW, Shimbo S, Moon CS, Watanabe T, Nakatsuka $\mathrm{H}$, et al. Correlation between concentration in urine and in blood of cadmium and lead among women in Asia. Sci Total Environ. 2000;246:97-107.

27. Kim JH, Lee JY, Seo JE, Jeong JY, Jung KK. Lead, cadmium and mercury levels in the 2010 Korean diet. Food Add Contamin. 2012;5:260-4.

28. Lee JW, Lee CK, Moon CS, Choi IJ, Lee KJ, Yi S-M, et al. Korea national survey for environmental pollutants in the human body 2008: heavy metals in the blood or urine of Korean population. Int J Hyg Environ Health. 2012;215:449-57.

29. Mutlu A, Lee B-K. Air-borne lead levels in the Korea peninsula; characterization of temporal and spatial patterns and cancer risk analysis. Environ Sci Pollut Res. 2012;19:2125-37.

30. Ha M, Kwon HJ, Leem JH, Kim HC, Lee KJ, Park I, et al. Korean Environmental Health Survey in children and adolescents (KorHS-C): Survey design and pilot study results on selected exposure biomarkers. Int $\mathrm{J}$ Hyg Environ Health. 2014;217:260-70. 